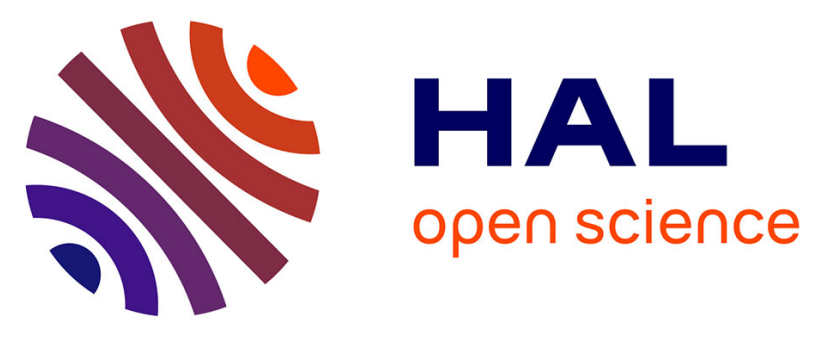

\title{
3D printing: rapid manufacturing of a new small-scale tidal turbine blade
}

Marwane Rouway, Mourad Nachtane, Mostapha Tarfaoui, Nabil Chakhchaoui, Lhaj El Hachemi Omari, Fouzia Fraija, Omar Cherkaoui

\section{- To cite this version:}

Marwane Rouway, Mourad Nachtane, Mostapha Tarfaoui, Nabil Chakhchaoui, Lhaj El Hachemi Omari, et al.. 3D printing: rapid manufacturing of a new small-scale tidal turbine blade. International Journal of Advanced Manufacturing Technology, 2021, 10.1007/s00170-021-07163-7 . hal-03242617

\section{HAL Id: hal-03242617 \\ https://hal-ensta-bretagne.archives-ouvertes.fr/hal-03242617}

Submitted on 3 Jun 2021

HAL is a multi-disciplinary open access archive for the deposit and dissemination of scientific research documents, whether they are published or not. The documents may come from teaching and research institutions in France or abroad, or from public or private research centers.
L'archive ouverte pluridisciplinaire HAL, est destinée au dépôt et à la diffusion de documents scientifiques de niveau recherche, publiés ou non, émanant des établissements d'enseignement et de recherche français ou étrangers, des laboratoires publics ou privés. 


\title{
3D printing: Rapid Manufacturing of a New Small-scale Tidal Turbine Blade
}

\author{
Marwane Rouway $^{* 1,2}$, Mourad Nachtane ${ }^{3}$, Mostapha Tarfaoui ${ }^{4}$, Nabil Chakhchaoui ${ }^{2,5}$, \\ Lhaj EI Hachemi Omari ${ }^{1}$, Fouzia Fraija ${ }^{1}$, Omar Cherkaoui ${ }^{2}$ \\ ${ }^{1}$ Hassan II University, Faculty of Sciences Aïn Chock, LERDYS and LPMMAT Laboratories, BP 5366 Maarif, \\ 20100 Casablanca, Morocco \\ ${ }^{2}$ REMTEX Laboratory, Higher School of Textile and Clothing Industries (ESITH), Casablanca, Morocco \\ ${ }^{3}$ LEM3-UMR 7239 CNRS, Arts et Métiers ParisTech Metz, 4 Rue Augustin Fresnel, 57078 Metz, France \\ ${ }^{4}$ ENSTA Bretagne, IRDL, UMR, CNRS 6027, F-29200, Brest, France \\ ${ }^{5}$ BGIM Laboratory, Higher Normal School (ENS), Hassan II University, Casablanca, Morocco. \\ *Corresponding author: marwanerouway@gmail.com \& mourad.nachtane@ensta-bretagne.org
}

\begin{abstract}
The 3D printing technology used for small tidal and wind turbines has great potential to change and overcome certain weaknesses in traditional manufacturing techniques. In rural areas and isolated communities, small turbine systems could be locally fabricated and assembled by using additive manufacturing machines and also can be employed to decrease residential energy consumption. The objective of the paper is to study the thermomechanical performance of 3D printing of a small-scale tidal turbine blade and their process using Digimat-AM because more research efforts are needed in this area. In this work, the tidal turbine blade is printed by using the Selective Laser Sintering SLS method with Polyamide 12 (PA12) and Polyether ether ketone (PEEK) polymers reinforced by carbon beads (CB) and glass beads (GB). This research examines conceptual considerations of small tidal turbines including material properties and aerodynamic parameters. Once the finite element evaluation has been completed, the deflection, residual stresses, temperature distribution, and the deformed blade or warpage can be obtained. It is concluded that PA12-CB has warpage higher than PA12-GB by $3.78 \%$, and PEEK-CB has warpage lower than PEEK-GB by $8.4 \%$. Also, the warpage of PA12-CB is lower than PEEK-CB by $10.31 \%$, and the warpage of PA12-GB is lower than PEEK-GB by $20.95 \%$. Therefore, the lowest warpage is observed for PA12-GB. Finally, the results showed that 3D printing presents an excellent opportunity in the design and development of tidal energy systems in the future.
\end{abstract}

Keywords: 3D printing, Small tidal turbine, Selective Laser Sintering, Warpage, Deflection 


\section{Introduction}

To respond to the growing energy consumption, the world has come together to fight this problem by increasing the use of renewable energies and this led to the development of a new sector of energy in which ocean energy is used for energy production because oceans cover $70 \%$ of the world's surface [1]. Several studies have confirmed that tidal currents have great potential as a predictable sustainable resource for industrial scale production of electrical power $[2,3]$. In this context, tidal current turbine (TCT) is used to harness energy from marine currents, especially small horizontal and vertical axis tidal turbine HATT or VATT, which can operate in less deep and less powerful currents [4]. Many types of tidal current turbine, based metal materials or composites, were considered and tested. A practice of composites in marine structures, particularly for offshore utilization, is appeared [5]. The importance of small tidal turbine is cheaper, easy and faster in manufacturing, which can help isolated communities in power production. Generally, the small tidal turbine can be manufactured using 3D printing technology. Additive manufacturing allows the automatic construction of 3D components by the accumulation of basic materials. 3D printing technology applied in the turbine fabrication sector faces many obstacles, such as inadequate space for construction, cost, engineering effort and timeconsuming, in addition to the lack of 3D models. Additive manufacturing is widely used in many areas, such as buildings [5-8], bridges [9], automobiles [10-12], sports and medical equipment [1315], wind turbines [16, 17], marine vehicles [18], engines [19-21], rotating wings [22] and water tunnel testing [23]. The environmental impact of additive manufacturing using 3D printing technology is the reduction of waste, it can reduce waste by $40 \%$ [24]. Since the building material is printed layer by layer, there is almost no waste during production.

The technology of 3D printing is used in wind turbines blade manufacturing with rapid prototyping, in which the printed part is tested by the engineers before the large-scale production. 3D printing has been used in aerospace technology to produce aerodynamic models [25], prototype hydro-turbines [26], and micro-wind turbines [27]. The design of small turbines as consumer-level components assemblage of the $3 \mathrm{D}$ printer has great potential to reduce costs, minimize waste, and improve the accessibility of wind turbine blades. This approach exceeds the rapid prototyping method and allows for a rapid manufacturing of the final product. [28]. These turbines can be used to provide energy in rural and isolated areas, and can be produced drastically at low cost through on-site manufacturing, with minimal tooling and low-cost filamentary material [29, 30]. The RepRap 3D printer is employed to design wind turbines on a self-replicating approach. Several requirements must be taken into account using the self-replication approach, including material properties, turbine size according to printer size, reinforcement techniques and print optimization [28]. This manufacturing approach could be implemented for other renewable energy technologies, particularly for small hydroelectric turbines, which can produce higher power than wind turbines [17]. The Venecia style of wind turbine has been studied based on numerous prototypes [29] and manufactured by rapid prototyping. This design style 
applies to both vertical and horizontal configurations. Vestas is another company that has its 3D printing facilities for rapid prototyping and product development. This has allowed Vestas to control the value chain in manufacturing, transportation, installation and service of the final product [31]. Also, LM Wind Power used 3D printing technology for rapid blade prototyping [32]. This will reduce the cost of producing wind turbine blades and other components. According to [33], the interesting aspects of AM in the wind turbine industry are the integration of internal channels, the fabrication of lightweight structures, and the integration of functions. Also, the wind industry is moving into smallscale 3D component printing. It will then move to a larger scale [33].

Poole et al. [34] manufactured a small wind turbine blade using the FDM method, which indicates low-cost effectiveness per blade and it depends on the size and reinforcement materials. Under testing tunnel, the favoured method with precise geometry accuracy is the pultruded rod reinforced. Olasek et al. [35] investigated the NACA0018 profile which is manufactured with different 3D printing methods. The results proved that this new type of additive manufacturing can be used in tough and complicated geometries; also it is quick and cheap. The choice of 3D technology depends on many parameters (size, material, geometry, fitted surface ...).

In this paper, a new small-scale tidal turbine blade is fabricated using computational 3D printing through Digimat-AM which simulates the printed part process. Thus serve professionals and designers to detect difficulties during the manufacturing process. The objective of the AM simulation is the prediction of the deformation, the residual stresses and the temperature distribution of the final part. The obtained results showed that additive manufacturing plays important role in the rapid prototyping of the tidal turbine blade for power generation. The 3D printing of wind turbines is already investigated in many of the previously mentioned works. The novelty of this work is the use of $3 \mathrm{D}$ technology for the manufacturing of tidal current turbine (TCT).

\section{Method and Materials}

\subsection{Aerodynamic and geometry of hydrofoil}

When a hydrofoil is subjected to water flow, the velocity affects the geometry of the hydrofoil by causing a pressure difference between the upper (extrados) and lower (intrados) sides as seen in Figure 1. In general, hydrofoils are designed to have a higher pressure which is translated into a force perpendicular to the relative velocity called the lift force $L$. There will also be a force acting parallel to the direction of the relative velocity which will be the result of the hydrofoil's resistance to the movement of the fluid called the drag force $D$. These forces are usually converted to dimensionless numbers called the coefficient of lift $C_{L}$ and the coefficient of drag $C_{D}$ as seen below:

$$
C_{L}=\frac{L}{0.5 \rho V^{2} A} \quad C_{D}=\frac{D}{0.5 \rho V^{2} A}
$$


Where $\rho$ is the density of seawater $\left(\mathrm{kg} / \mathrm{m}^{3}\right), \mathrm{V}$ is the non-uniform velocity of seawater $(\mathrm{m} / \mathrm{s}), \mathrm{A}$ is the turbine blade area $\left(\mathrm{m}^{2}\right), \mathrm{L}$ and $\mathrm{D}$ is the force of lift and drag respectively.

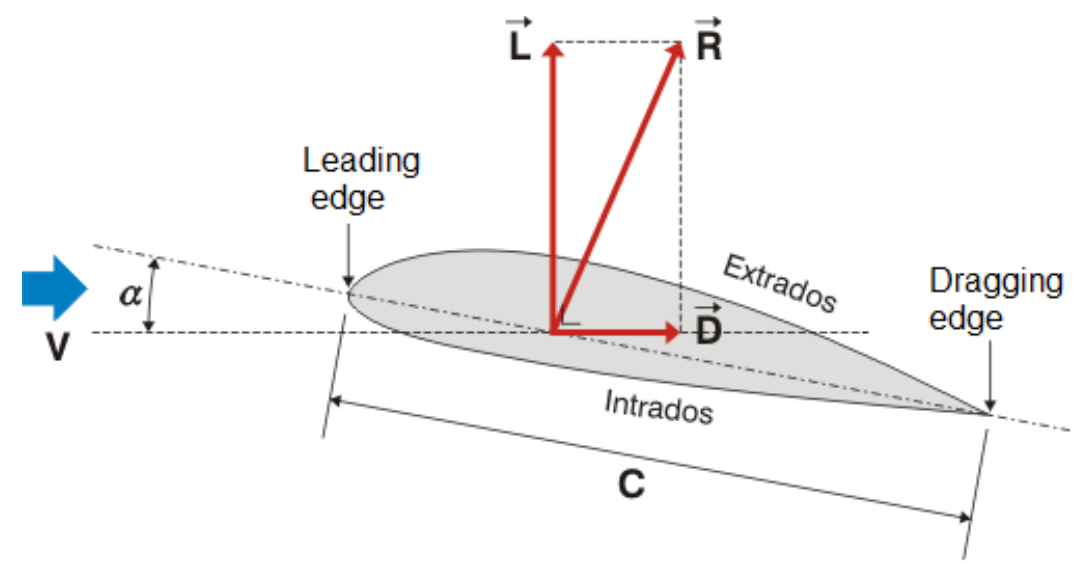

Figure 1. Characteristic of the hydrodynamic profile.

In this work, The FX 74-CL5-140 profile was used as a reference for the optimization of a new hydrofoil, by modifying its maximum camber and maximum thickness to improve its hydrodynamic performance. FX74-CL5-140 profile has high lift adapted to low speed (Reynolds). The optimized profile was the most useful to function as a hydrofoil for tidal turbines, with $10 \%$ growth in camber and 20\% thickness. The name of the profile is NTSXX20 (Nachtane-Tarfaoui-Saifaoui-XX20) which developed by the team of ENSTA Bretagne [36] as shown in Figure 2.

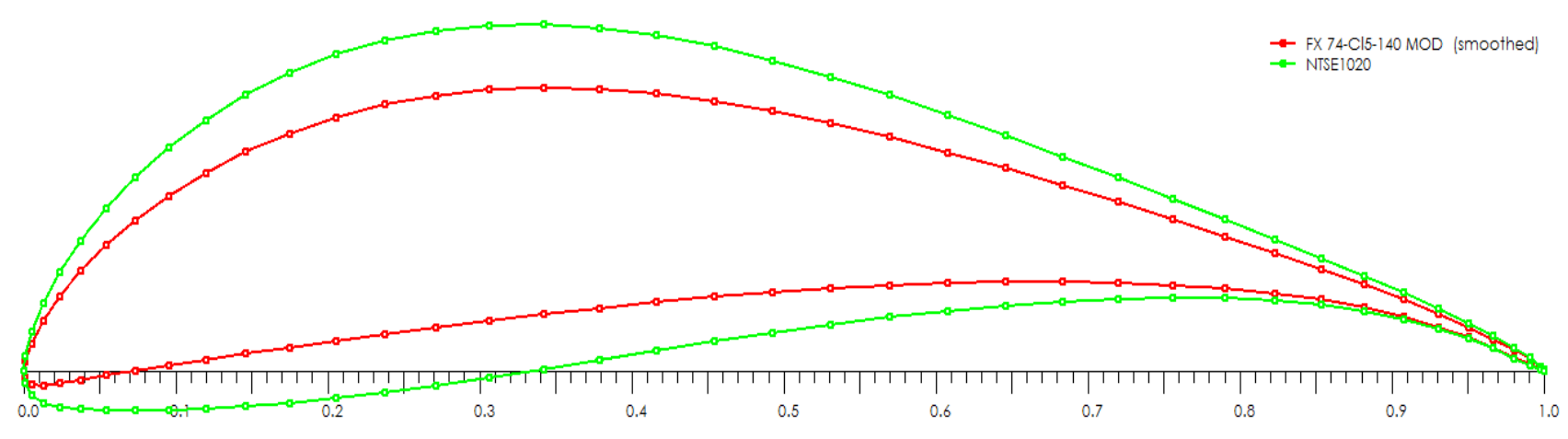

Figure 2. The geometry parameters of the developed NTSXX20 hydrofoil in comparison with FX74-

\section{CL5-140}

The new hydrofoil (NTSXX20) has very excellent hydrodynamic performance with high drag coefficient $C_{D}$ and low lift coefficient $C_{L}$ in comparison with the reference hydrofoil (FX74-CL5-140). Also, it has a high thickness in comparison with FX74-CL5-140, providing better strength and resistance to the blade structure, Figure 3. 


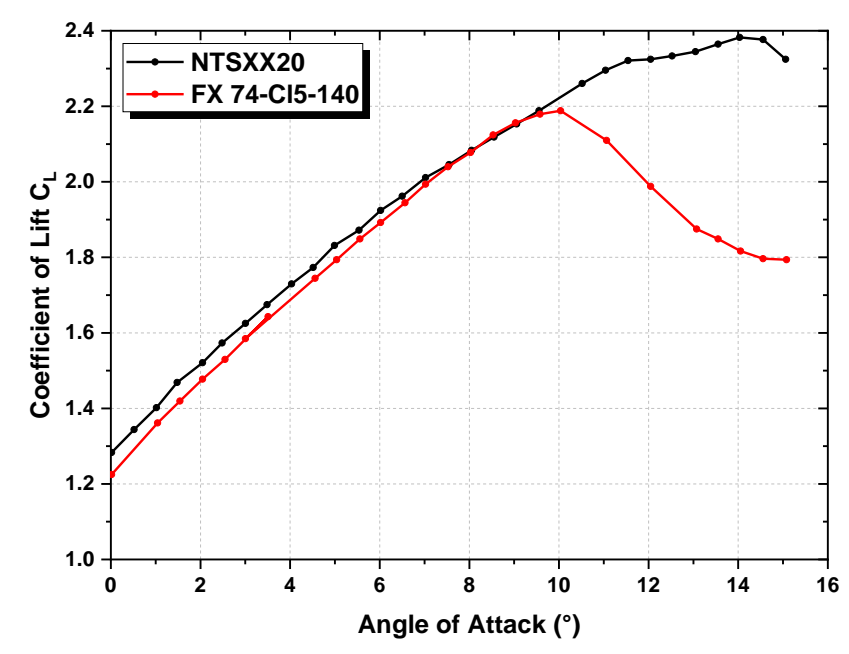

(a)

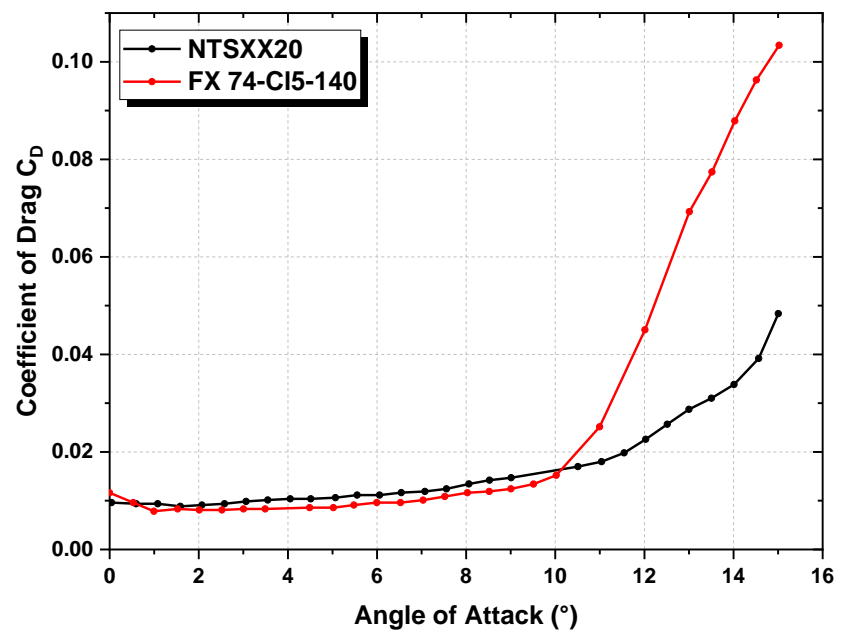

(b)

Figure 3. Aerodynamic coefficients of lift $C_{L}$ and drag $C_{D}$ of the new hydrofoil NTSXX20 in comparison with FX74-CL5-140 at the different attack of angle AOA and $\mathrm{Re}=2 \cdot 10^{6}$.

Based on the analysis of the ideal tidal turbine, some considerations design must be respected:

- The turbine should be easily printed by economical 3D printers.

- Design the tidal turbine where the scanned surfaces can be adapted within the geometric limit size of a $3 \mathrm{D}$ printer.

- Use material reinforcement techniques to increase the life cycle and reducing warpage.

\subsection{Material properties}

In this research project, the thermoplastics polymers PA12 and PEEK are used to print the tidal turbine blade. These materials are employed in printing applications due to their high mechanical strength, flexibility without fracture, biocompatibility and economic [37-40]. This explains the use of PA12 and PEEK materials in additive manufacturing processes, such as the creation of functional parts and prototypes. The thermomechanical properties of PA12 and PEKK are presented in Figure 4. It can be noted that PEEK has improved mechanical properties compared to PA12, with a high Young's modulus, Figure 4a. On the other hand, PA12 has enhanced thermal properties compared to PEEK, with a high specific heat capacity and coefficient of thermal expansion (CTE), Figure 4b. At a temperature of $23^{\circ} \mathrm{C}$, Young's modulus is $1200 \mathrm{MPa}$ for PA12 and $3800 \mathrm{MPa}$ for PEEK and the value of CTE is $610^{-5}{ }^{\circ} \mathrm{C}^{-1}$ for PA12 and $4.510^{-5}{ }^{\circ} \mathrm{C}^{-1}$ for PEEK. Also, with increasing temperature, the density and Young's modulus decreases, and the CTE and specific heat capacity increase. CB and GB fillers properties in normal conditions $23^{\circ} \mathrm{C}$ are depicted in Table 1 . 

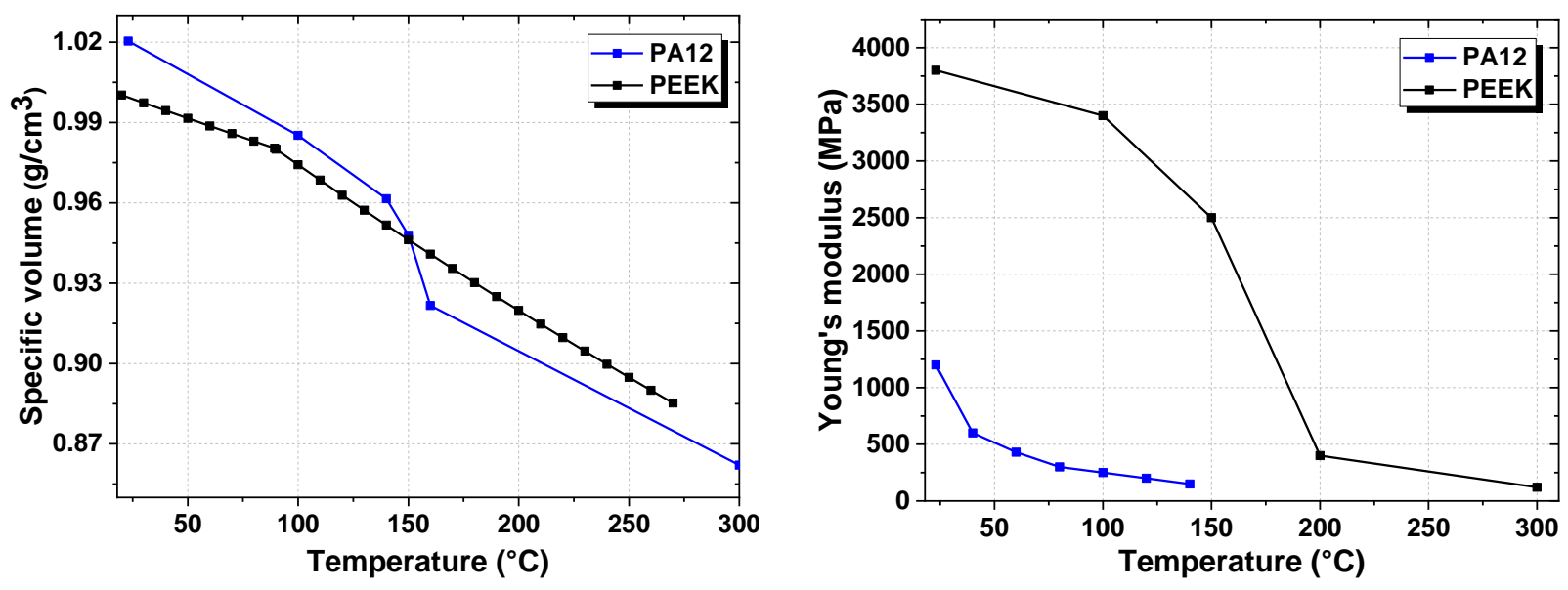

(a)
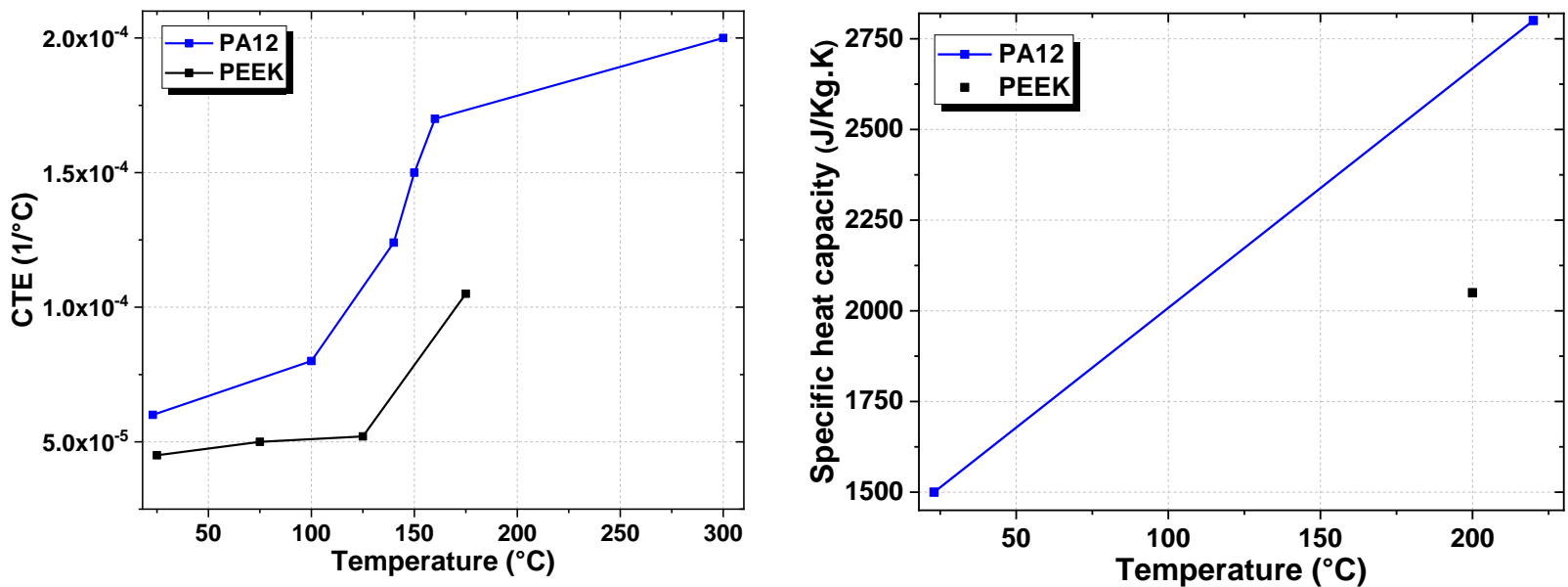

(b)

Figure 4. Thermomechanical properties of thermoplastics polymers

Table 1. Thermomechanical properties of fillers

\begin{tabular}{lcc}
\hline & Carbone beads (CB) & Glass beads (GB) \\
\hline Density $\left(\mathbf{g} / \mathbf{c m}^{3}\right)$ & 1.78 & 2.54 \\
Young's modulus (MPa) & $2.3 \cdot 10^{5}$ & $72 \cdot 10^{3}$ \\
Poisson ratio & 0.2 & 0.22 \\
CTE $\left(\mathbf{1} /{ }^{\circ} \mathbf{C}\right)$ & $2 \cdot 10^{-6}$ & $6 \cdot 10^{-6}$ \\
\hline
\end{tabular}

\subsection{Numerical 3D printing process}

The 3D printing by AM process begins with the design of the hydrofoil geometry in 3D CAD software. In this works, Digimat-AM is employed to simulate different material configurations and to predict and evaluate the performance of parts fabricated by additive manufacturing. Figure 5 gives a summary of the various stages to create a tidal turbine blade using computational simulation. It is noted that $3 \mathrm{D}$ printing depends on several parameters such as the type of process, the material, the thermomechanical constraints, etc. However, not all parameters can be controlled; 3D printing can be 
different based on the CAD model with different residual stresses and warpage. According to the workflow given in Figure 5, the first stage is to define the part to print by importing the material properties and the initial geometry as an STL file. The printing materials chosen are PA12 and PEEK thermoplastics polymers due to their biocompatibility for tidal energy applications. The 3D printing process requires many parameters such as tool path and specific inputs in order to describe the manufacturing procedure. Then the AM process configuration is translated into a thermomechanical simulation and accounts for the heat transfer mechanisms inside the printer. During the simulation, the blade geometry is meshed by the voxel method to enable layer-by-layer modeling. After finite element simulation, the residual stresses of Von Mises, temperature field, and deformed blade can be obtained. The Selective Laser Sintering (SLS) technology is employed to print the tidal blade by PA12 and PEEK polymers reinforced by carbon and glass beads as resumed in Table 2. The SLS process involves sintering a plastic powder inside the solid part where a laser source melts the powder selectively by scanning the transverse sections created from the digital model of the printed part. By sintering a layer, a new procedure of sintering of the next layer begins by deposition of powder with a diameter of $0.05 \mathrm{~mm}$, and then the process is performed until the printing part is completed. The simulations of the 3D printing by SLS process include several steps that involve: heating the powder by sintering, and depositing the layer by laser scanning. The process parameters used in the printing of a tidal turbine blade are summarized in Table 3. These parameters are determined after performing an optimization problem, by selecting the most appropriate parameters to minimize stresses and warpage. The tidal turbine is printed vertically and divided into three zones; the cylindrical lower zone, the twisted middle zone, and the thinner upper zone.

Table 2. Materials used in printing simulation

\begin{tabular}{|c|c|c|c|}
\hline \multirow{5}{*}{ SLS method } & \multirow{4}{*}{ Reinforced beads } & \multirow{2}{*}{$\mathrm{CB}$} & PA12 \\
\hline & & & PEEK \\
\hline & & & PA12 \\
\hline & & GB & PEEK \\
\hline & Unfilled & - & PA12 \\
\hline
\end{tabular}


Table 3. Process parameters used for tidal turbine blade printing

\begin{tabular}{lll}
\hline Parameters & Unit & Value \\
\hline Chamber temperature & ${ }^{\circ} \mathrm{C}$ & 330 \\
Laser power & $\mathrm{mW}$ & 48000 \\
Convection coefficient & $\mathrm{mW} /\left(\mathrm{mm}^{2} \cdot{ }^{\circ} \mathrm{C}\right)$ & 0.015 \\
Cooling time & $\mathrm{s}$ & 0 \\
Scan spacing & $\mathrm{mm}$ & 0.15 \\
Recoating time & $\mathrm{s}$ & 10 \\
Scan speed & $\mathrm{mm} / \mathrm{s}$ & 12500 \\
Beam diameter & $\mathrm{mm}$ & 0.5 \\
\hline
\end{tabular}

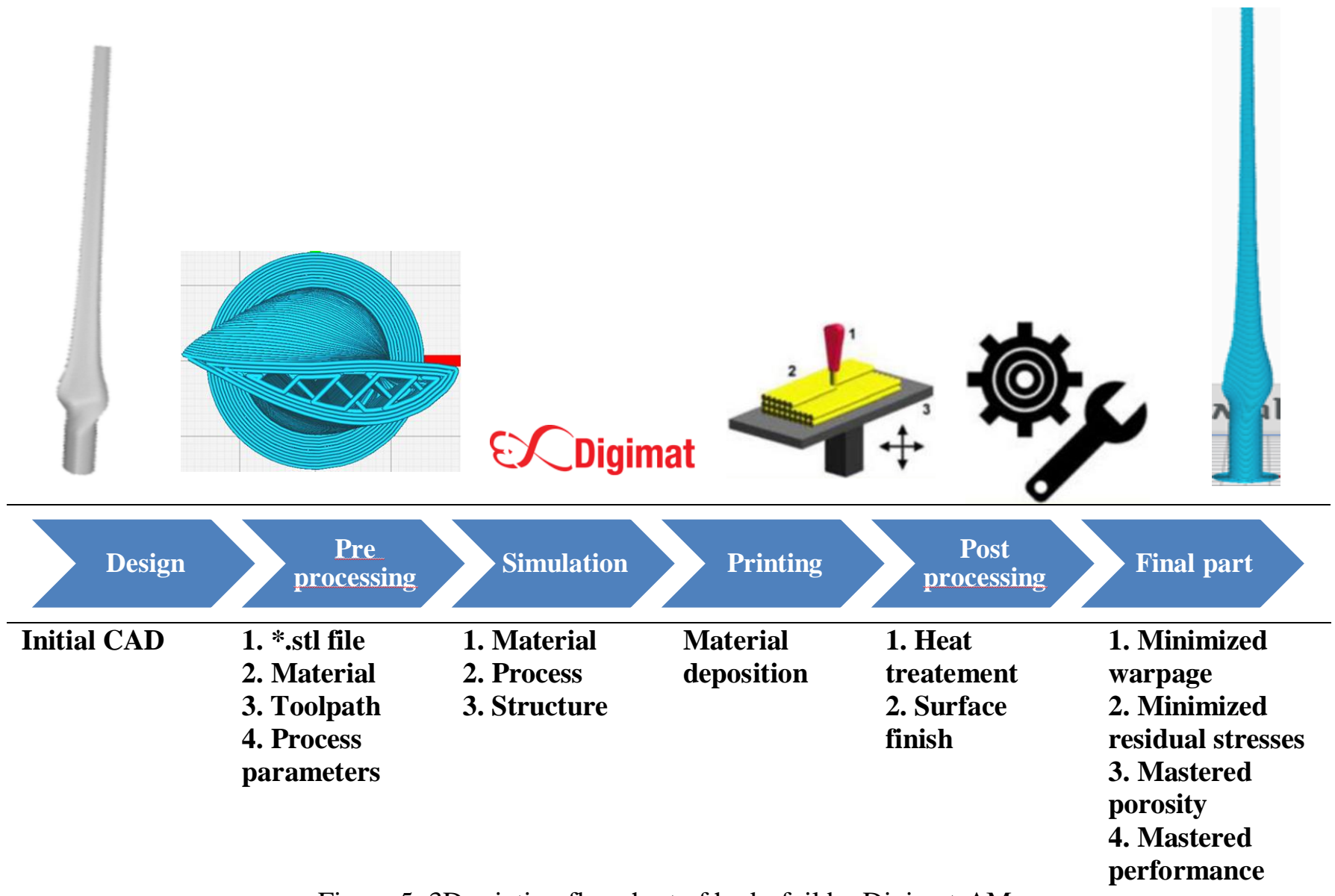

Figure 5. 3D printing flowchart of hydrofoil by Digimat-AM.

During the 3D printing simulation, there are three steps: printing, cooling and fitting. And for each step, Digimat-AM gives four informations about the printed part, which are: The mechanical deflection, the residual stresses of Von Mises, the temperature and the warpage. The detailed process is explained in Figure 6. 


\section{Printing step $\Rightarrow$ 2. Cooling step $\Rightarrow$ 3. Fitting step}

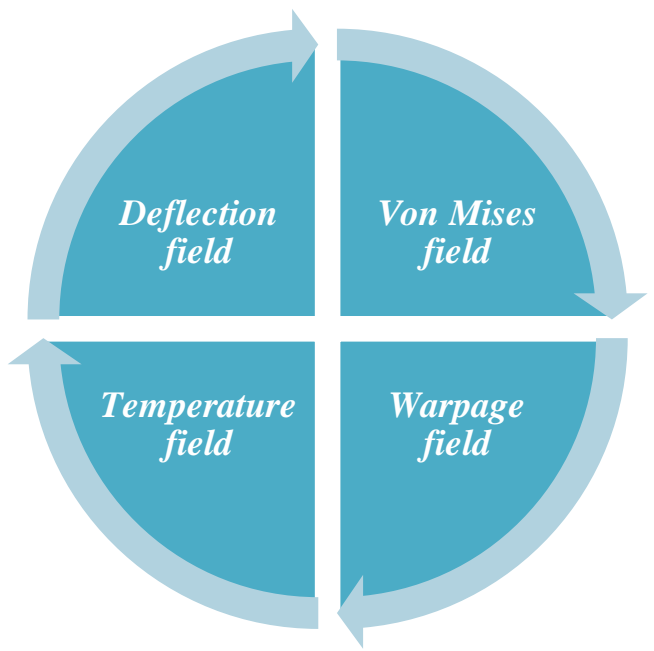

Figure 6. Digimat-AM flowchart during simulation of the printed tidal turbine

The images of the entire SLS process during the printing step are described in Figure 7.

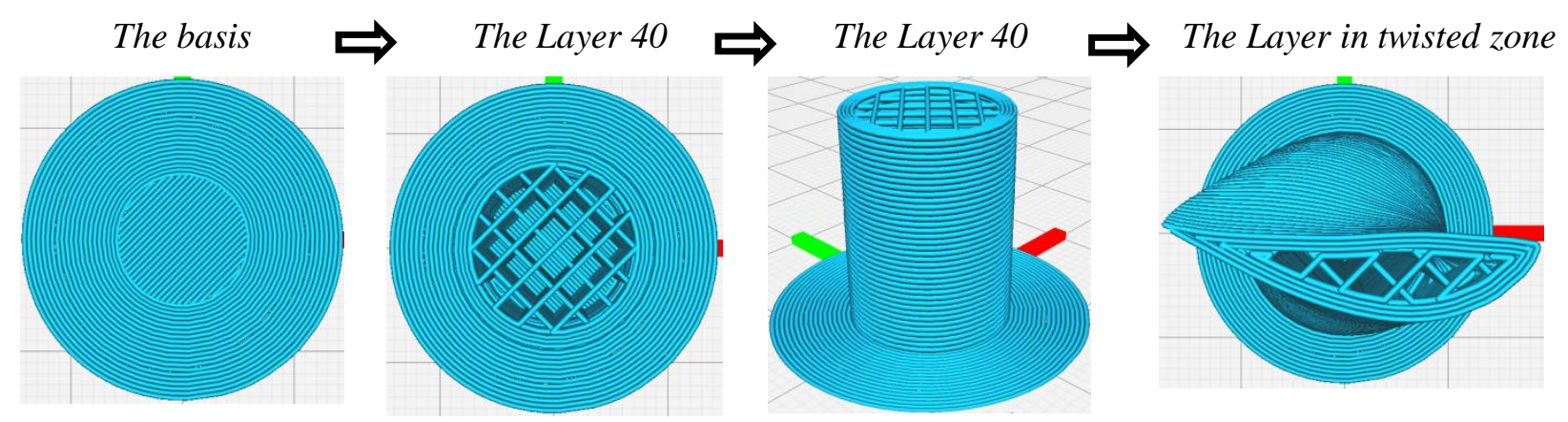

Figure 7. SLS process during 3D printing

The tidal turbine blade has been analyzed with thermomechanical and warpage type using DigimatAM. The dimension of the blade box geometry is considered as $(23-14-290 \mathrm{~mm})$ to fit the printer size and has been submitted to three manufacturing steps: printing, cooling, and warpage. During slicing, the layer thickness is $1 \mathrm{~mm}$ with 290 layers and the meshing size is $1 \mathrm{~mm}$ with 14755 voxels. The detailed dimensions of the tidal turbine are shown in Figure 8. 


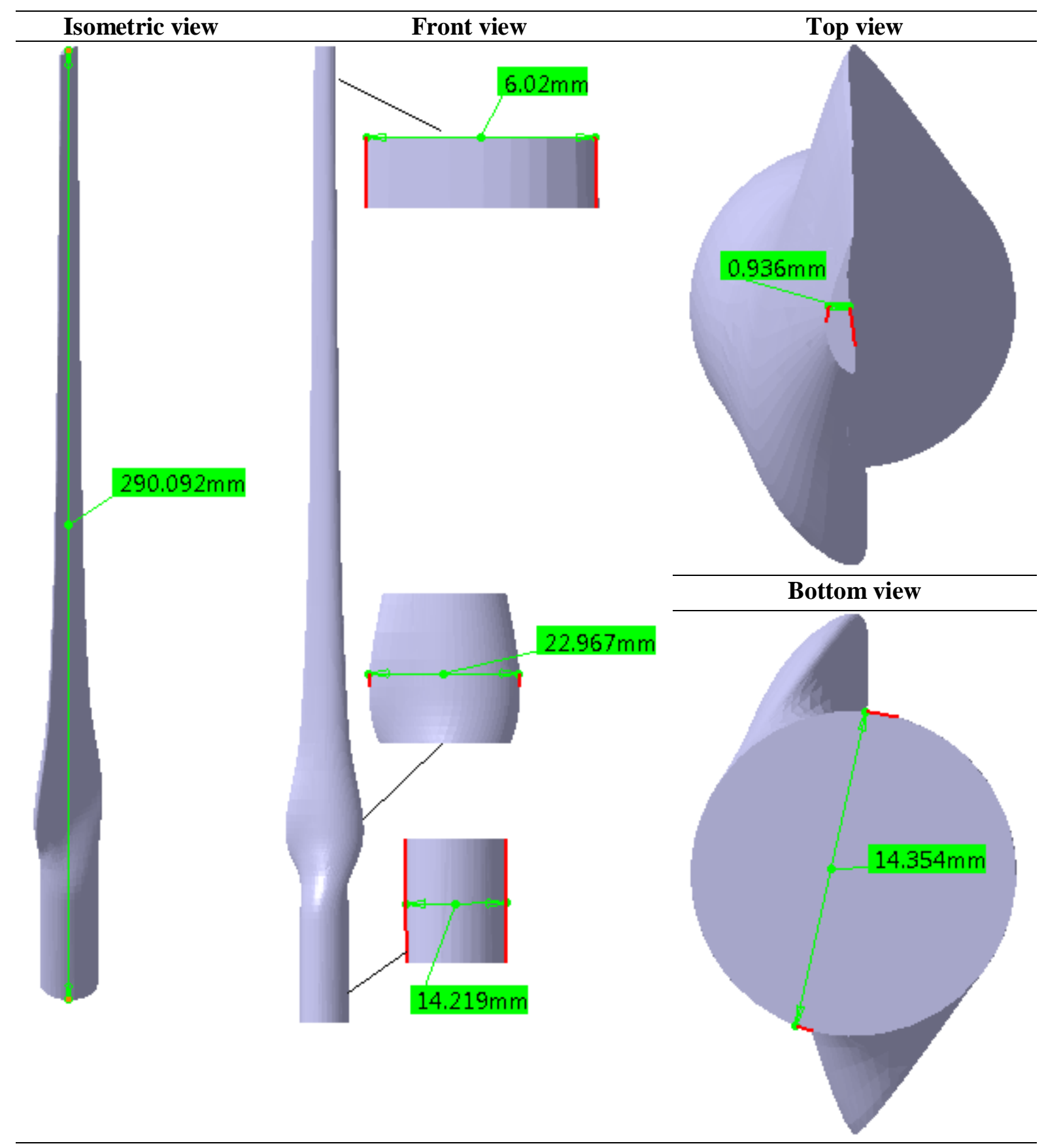

Figure 8 . The dimension of the tidal turbine blade

\section{Results}

The deflection fields show the change of geometry that occurs along the full manufacturing cycle, which generates residual stress between layers and used to analyze the warpage. It is very important to determine and control warpage when printing reinforced thermoplastic parts, and also to study the filling effect in resolving warpage problems. In this section, the results of the computational 3D printing for different materials PA12 and PEEK is presented with and without carbon and glass beads reinforcement. For each volume fraction of filler, the maximum and minimum values of the thermomechanical parameter are calculated in the final layer. 


\section{1. $\mathrm{CB}$ and GB reinforced PA12}

From Figure 9 and Figure 10, it can be seen that the addition of carbon reinforcement has a significant influence on the mechanical behavior of the PA12 printed blade. The deflection in printing step decrease in function of CB volume fraction, with a high value of $0.1055 \mathrm{~mm}$ for unmodified PA12 as mention in the twisted part of the blade (Figure 10a), and a low value of $0.06251 \mathrm{~mm}$ for $50 \mathrm{vol} \%$ as indicated in the upper thin part of the blade. The Von Mises residual stress increase in function of volume fraction (Figure 9b), from 1.095 MPa to $2.805 \mathrm{MPa}$ for the maximum value as observed in the lower circular section of the blade, and from $0.03393 \mathrm{MPa}$ to $0.2091 \mathrm{MPa}$ for minimum value as observed in the upper cylindrical part of the blade. The high residual stress is reached in the first printed layer, where this region is suffering from a major compression which makes it more critical. This result can be justified by the fact that the accumulated temperature gradient generates residual stresses. In the printing step, the minimum temperature value remains constant at $160^{\circ} \mathrm{C}$ (Figure $9 \mathrm{c}$ ), and the maximum temperature increase from $176^{\circ} \mathrm{C}$ to $179.7{ }^{\circ} \mathrm{C}$ due to the thermal conductivity of CB fillers. The general conclusion is that in cases where the volume fractions of the fillers are high, the warpage is very low (Figure 9d).

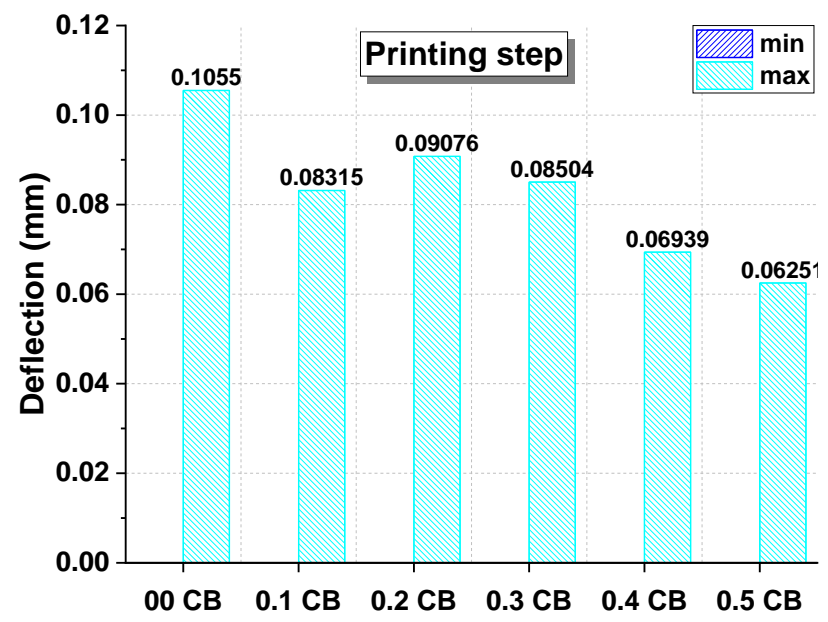

(a)

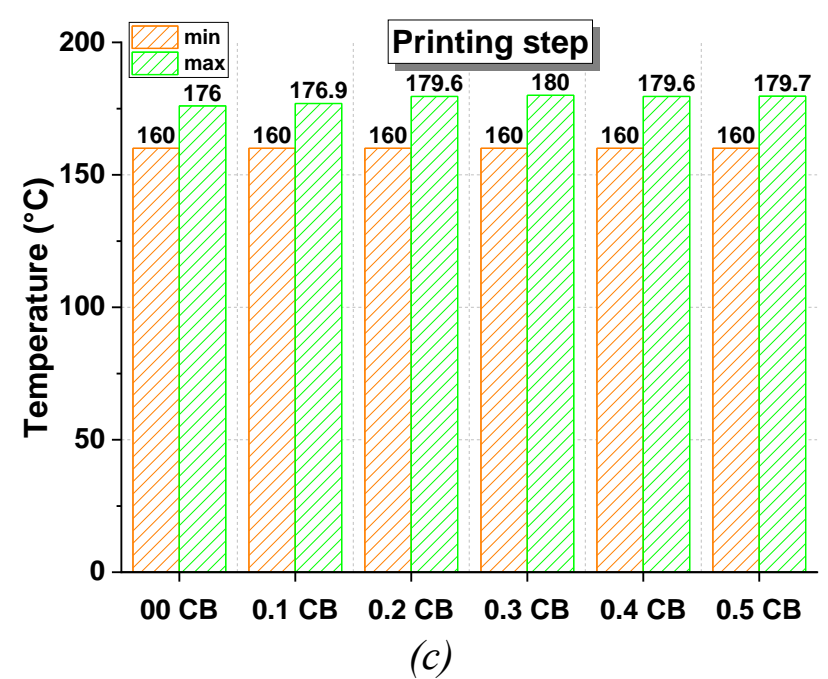

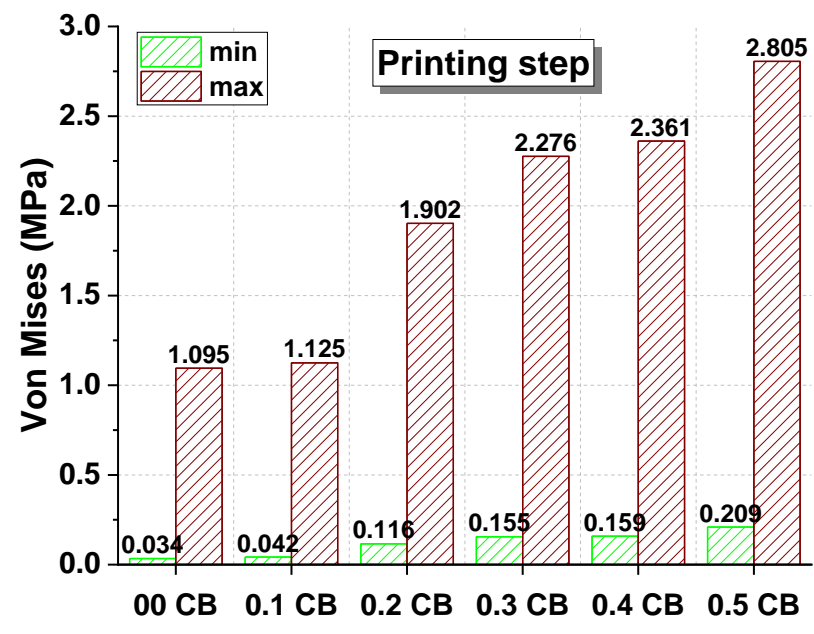

(b)

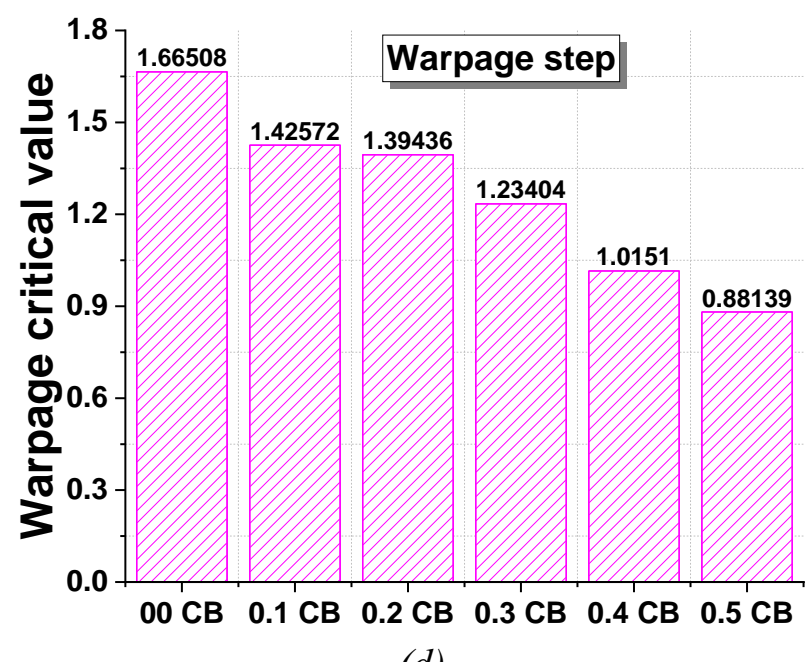

(d) 
Figure 9. Thermomechanical performances of carbon beads reinforced PA12 vs. volume fraction

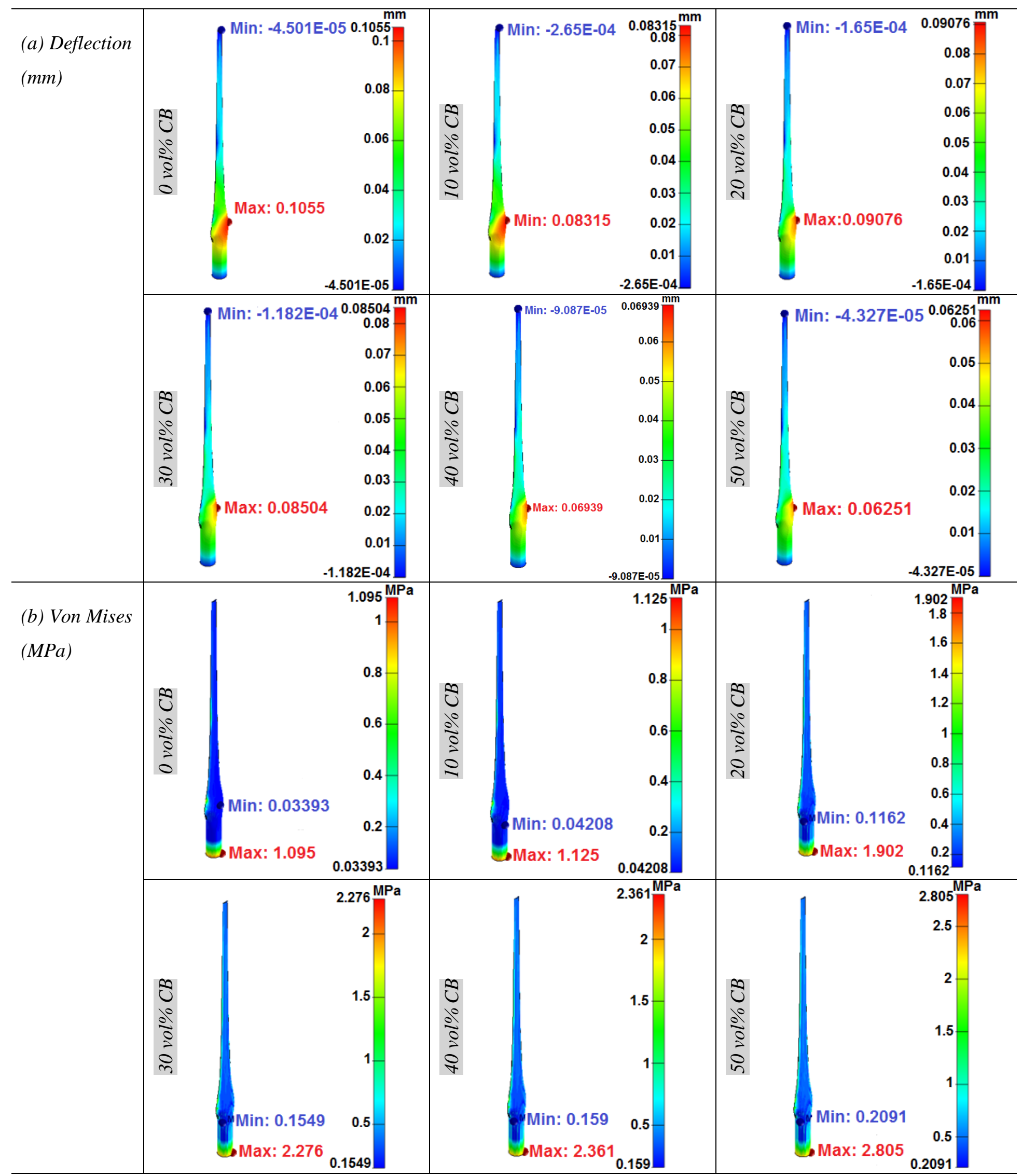

Figure 10. Deflection and residual stress (Von Mises) fields of carbon beads reinforced PA12 
For the glass beads-filled PA12 (Figure 11 and Figure 12), the results show that the maximum value of deflection and residual stresses reached $0.1055 \mathrm{~mm}$ and $2.429 \mathrm{MPa}$ respectively. In the volume fraction of $50 \%$ of GB, it can be noted that the deflection decreases and the maximum stress increases. This implies that the importance of GB to improve the mechanical performance of the printing blade. In addition, the warpage/deflection and stresses during printing rises after the cool down. AM demand multiple process and errors to achieve excellent consistency and expected performance after many simulations. The printed part could present significant warpage/deflection due to temperature gradientinduced distortion, thus dimensional tolerance may not be guaranteed. For the maximum volume fraction (50\%), the deflection and Von Mises of PA12-GB are lower than those of PA12-CB by $2.86 \%$ and $14.9 \%$ respectively (Figure 11a and b). During the printing step, the temperature field is minimal for $\mathrm{CB}$ of $179.7^{\circ} \mathrm{C}$ compared to $\mathrm{GB}$ of $183{ }^{\circ} \mathrm{C}$, which is explained by the high thermal conductivity of $\mathrm{CB}$ causing a very high convection rate (Figure 11c). In addition, the maximum warpage is lower for GB of 0.84808 than CB of 0.88139 (Figure 11d).

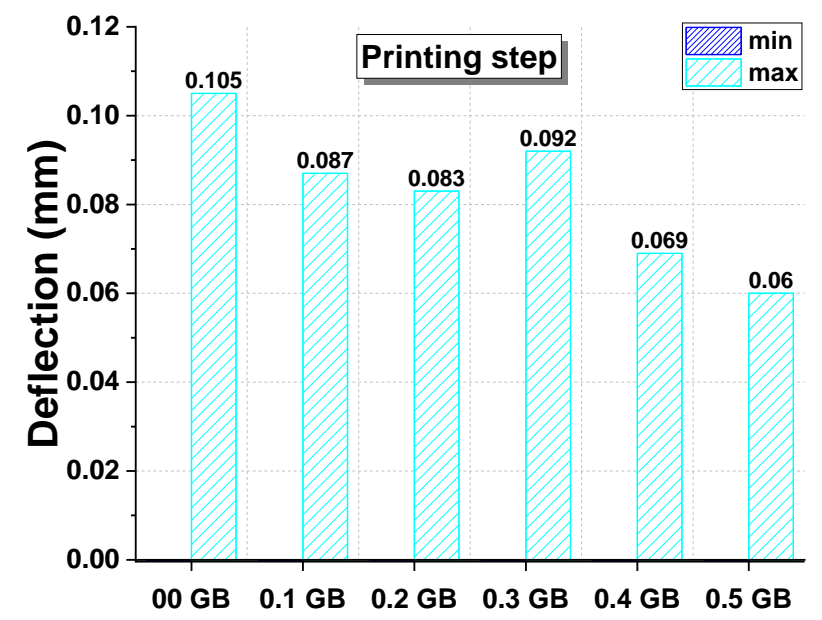

(a)

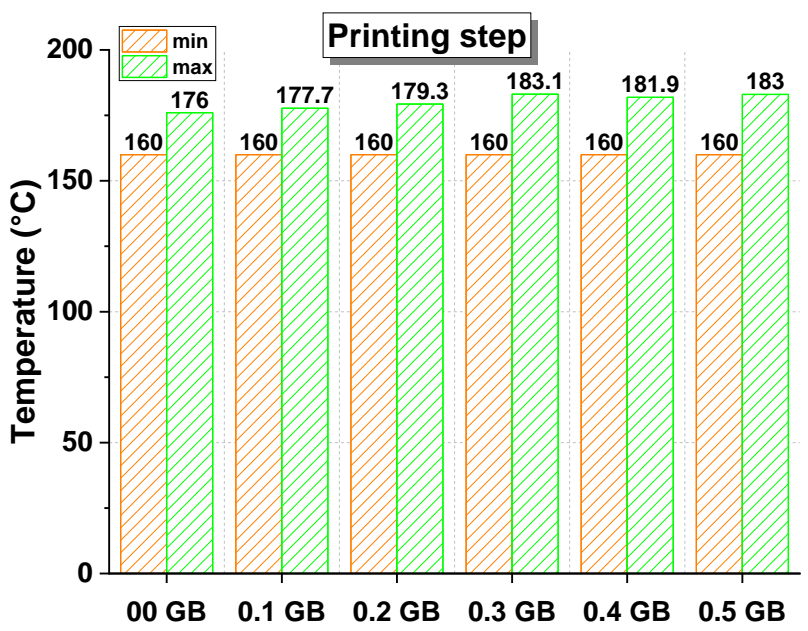

(c)

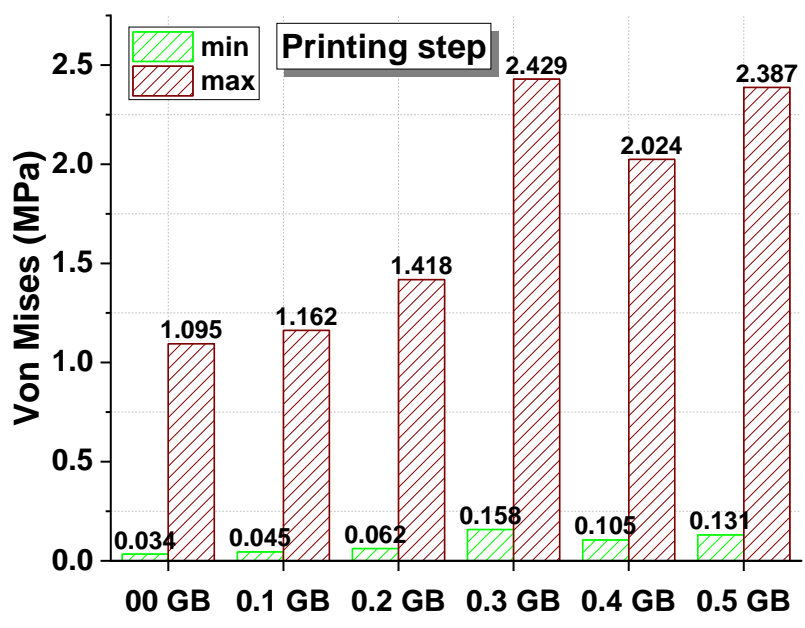

(b)

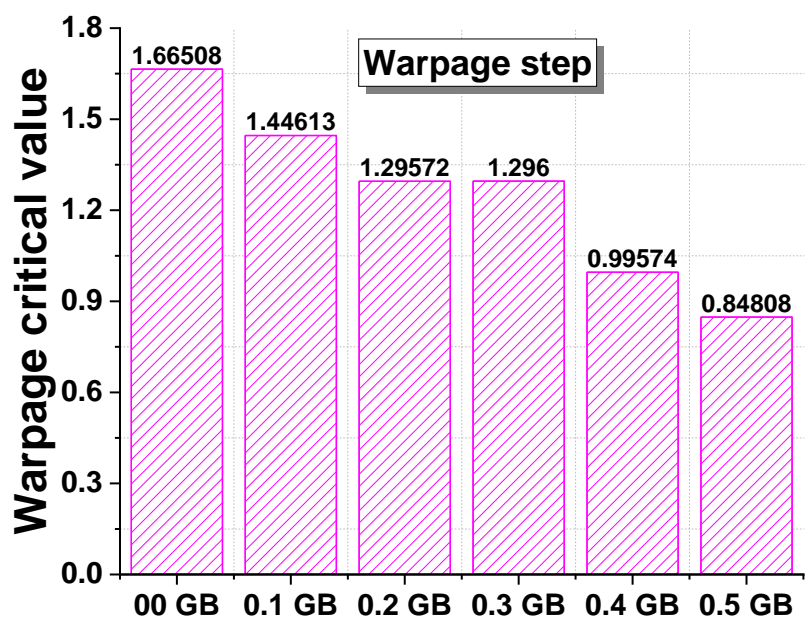

(d)

Figure 11. Thermomechanical performances of glass beads reinforced PA12 vs. volume fraction 


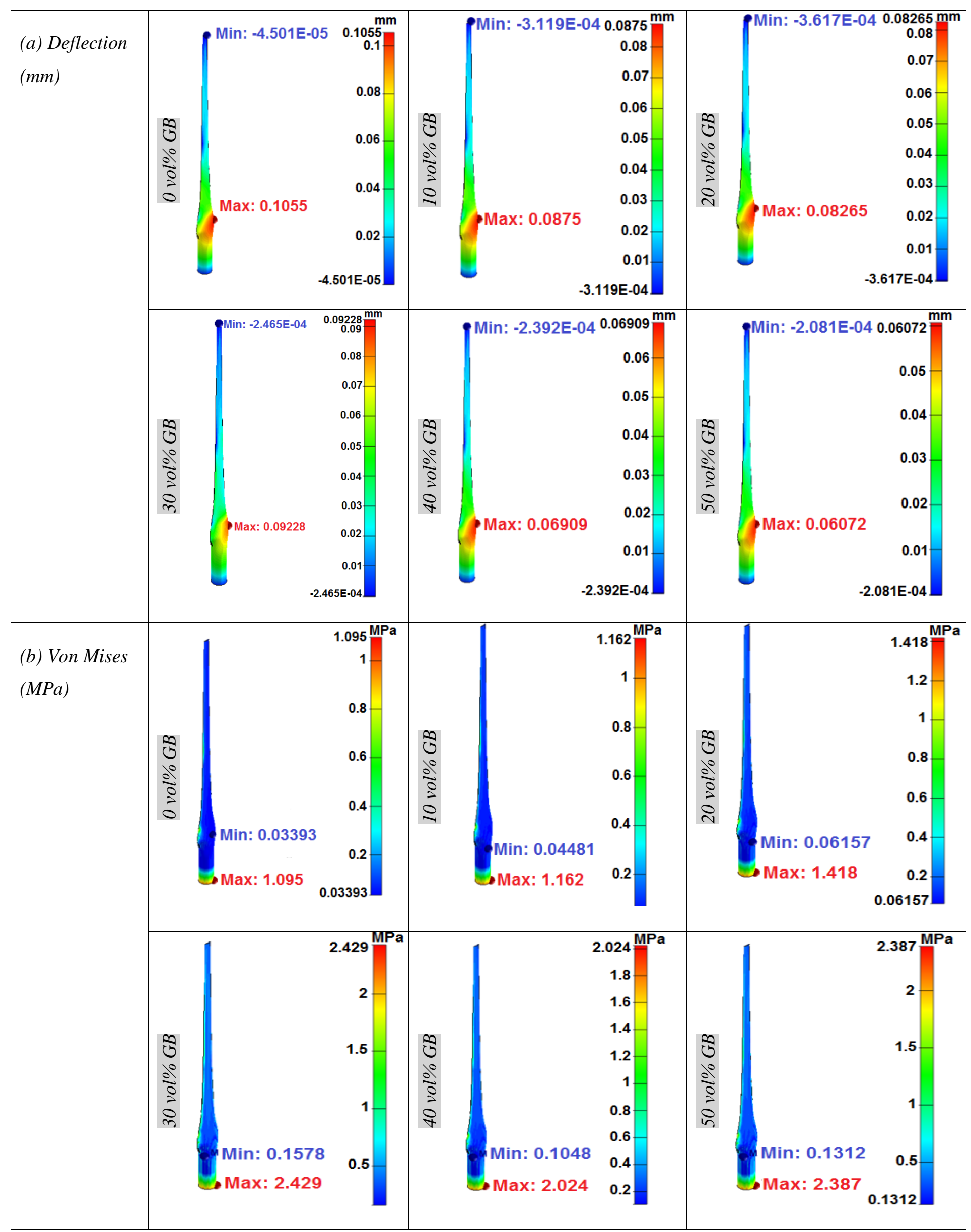


Figure 12. Deflection and residual stress (Von Mises) fields of glass beads reinforced PA12

\subsection{CB and GB reinforced PEEK}

The deflection is very small in the order of $0.01 \mathrm{~mm}$ compared to the volume fraction of $10 \%$ which has a maximum value of $2.882 \mathrm{~mm}$ in the upper part of the blade (Figure 13a). The residual stress is zero for unloaded PEEK with a maximum value of $0.5637 \mathrm{MPa}$ (Figure 13b). The addition of CB to PEEK increases the temperature at the end of the printing step from $173.5^{\circ} \mathrm{C}$ to $343.3^{\circ} \mathrm{C}$ (Figure $13 \mathrm{c}$ ). Also, for PEEK reinforced GB, the temperature increase from $173.5^{\circ} \mathrm{C}$ to $344.4^{\circ} \mathrm{C}$ (Figure $15 \mathrm{c}$ ). During the cooling process, the temperature of the printed tidal turbine returns to its ambient temperature of $23{ }^{\circ} \mathrm{C}$. The initial addition of a $10 \%$ volume fraction of CB caused a sharp increase in warpage with 1.91877, compared to the unmodified resin with 1.80993 (Figure 13d). But as more CB was incorporated, the warpage decreased linearly and eventually dropped below that of the unmodified neat polymer. The effect of high volume fraction of $\mathrm{CB}$ and GB fillers on thermomechanical properties of PEEK is summarized in Table 4, where the minimum warpage is observed for PEEK-CB with 0.98271 (Figure 14).

Table 4. Thermomechanical characteristics of reinforced PEEK at $50 \mathrm{vol} \%$

\begin{tabular}{lllll}
\hline & Deflection $(\mathbf{m m})$ & Von Mises (MPa) & Warpage & Temperature $\left({ }^{\circ} \mathbf{C}\right)$ \\
\hline PEEK-CB & 0.01686 & 0.5637 & 0.98271 & 343.3 \\
PEEK-GB & 0.0183 & 0.6218 & 1.07288 & 344.4 \\
\hline
\end{tabular}

The main interest from these simulations is to reduce as much as possible residual stresses and warpage. During printing, parts may show significant deformation, which requires compensation of this defect by using the warped geometry. A solution to circumvent the warpage includes the compensating of the geometry intended to be printed. Therefore, the as-printed geometry is close enough to the as-designed geometry. 


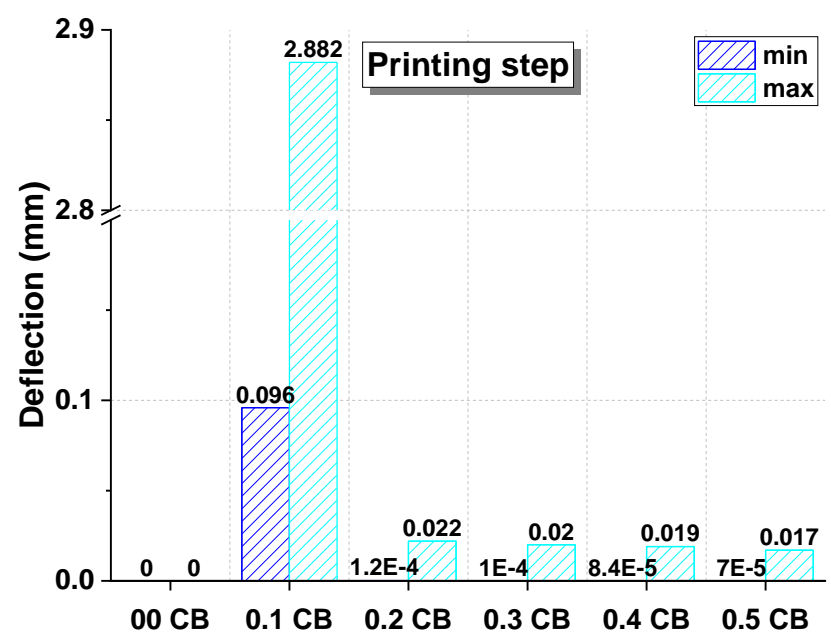

(a)

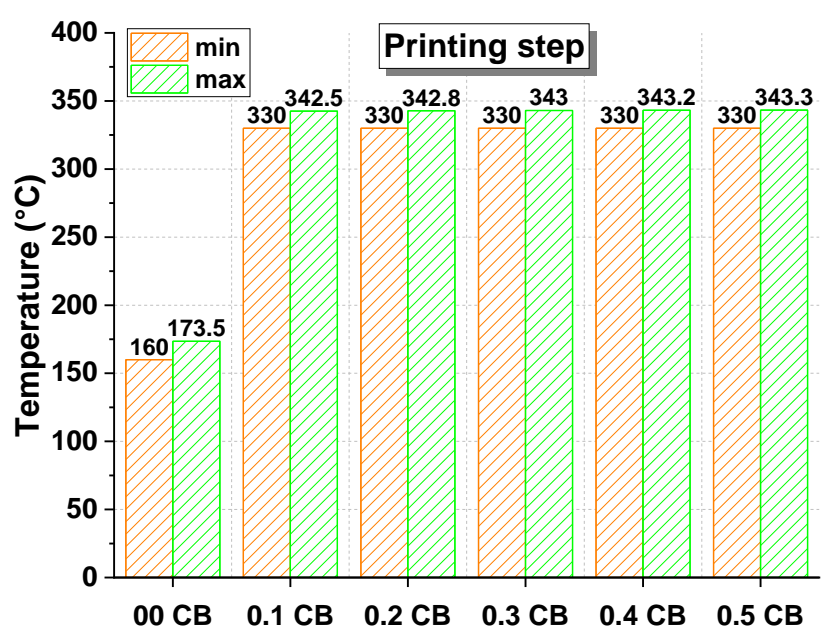

(c)

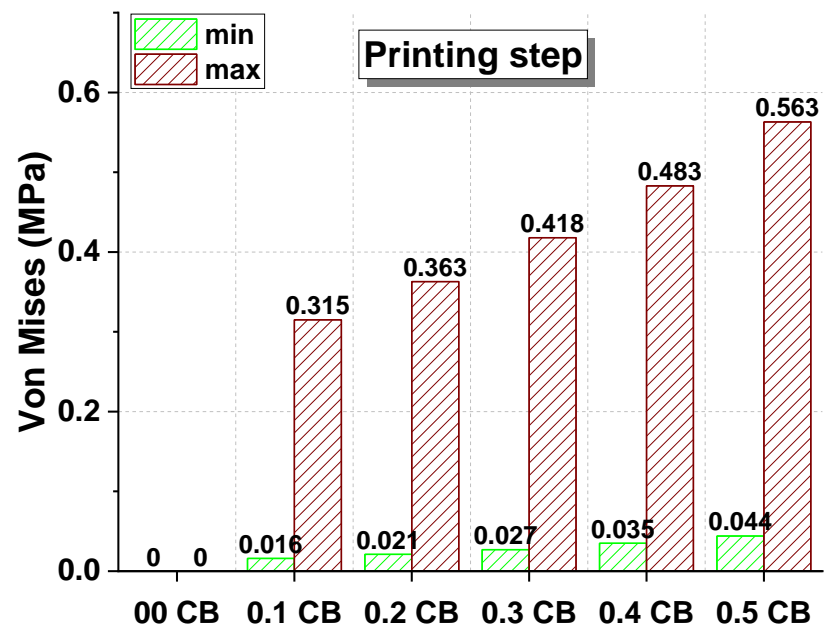

(b)

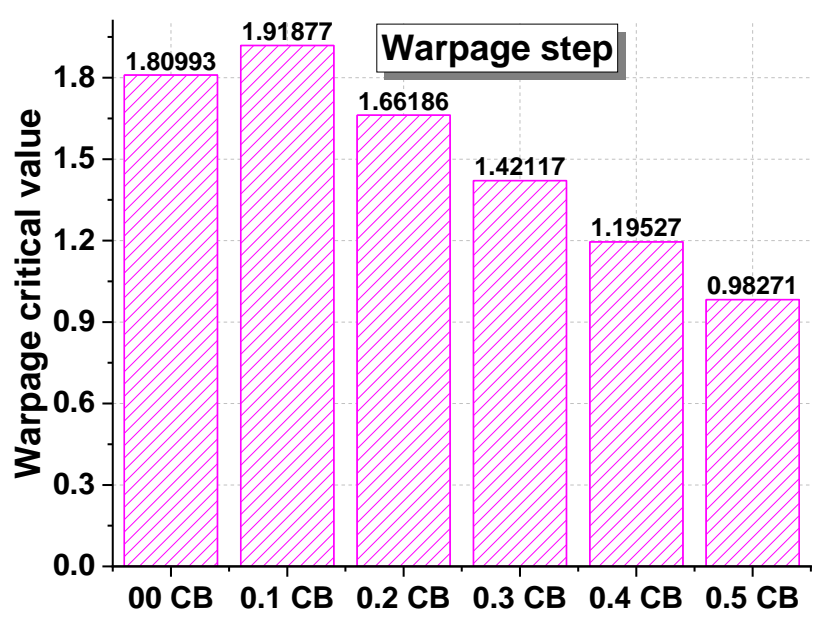

(d)

Figure 13. Thermomechanical performances of carbon beads reinforced PEEK vs. volume fraction 


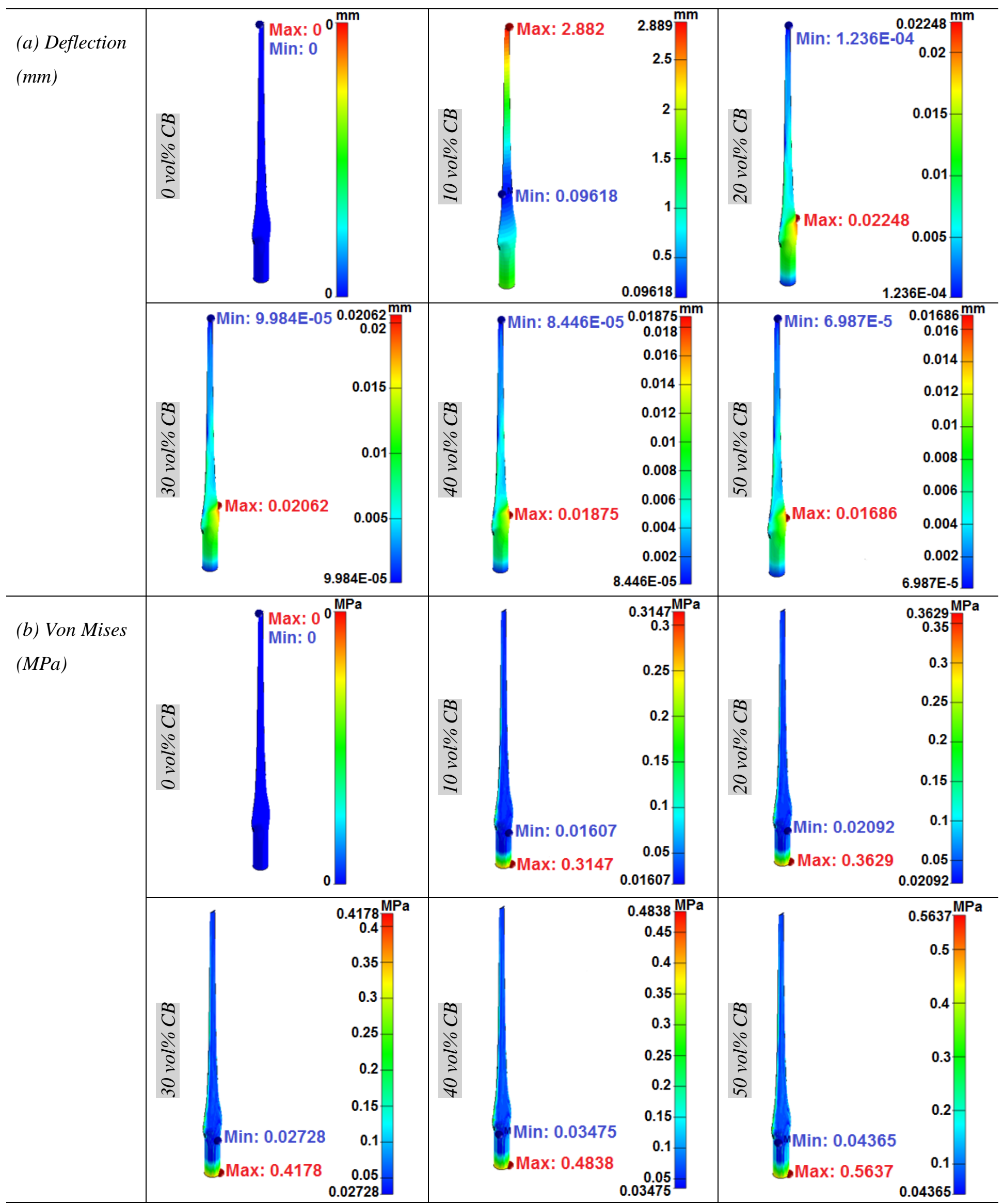

Figure 14. Deflection and residual stress (Von Mises) fields of carbon beads reinforced PEEK 
In order to compare with PEEK-CB, the thermomechanical properties of PEEK-GB have been evaluated as shown in Figure 15 and Figure 16, where the deflection of PEEK-CB is slightly lower than that of PEEK-GB (Figure 15a) because the mechanical stiffness of CB (230 E3 MPa) is higher than that of GB (72 E3 MPa). Also, the residual stress of PEEK-GB is large than that of PEEK-CB (Figure 15b), this is explained by the fact that if a material is rigid, then its residual stress, deflection and critical warpage are low and vice versa. The temperature field of GB is slightly larger than that of $\mathrm{CB}$ (Figure 15c) because of the thermal conductivity of $\mathrm{CB}$ which is higher than that of GB. This implies that PEEK-CB cools down rapidly compared to PEEK-GB.

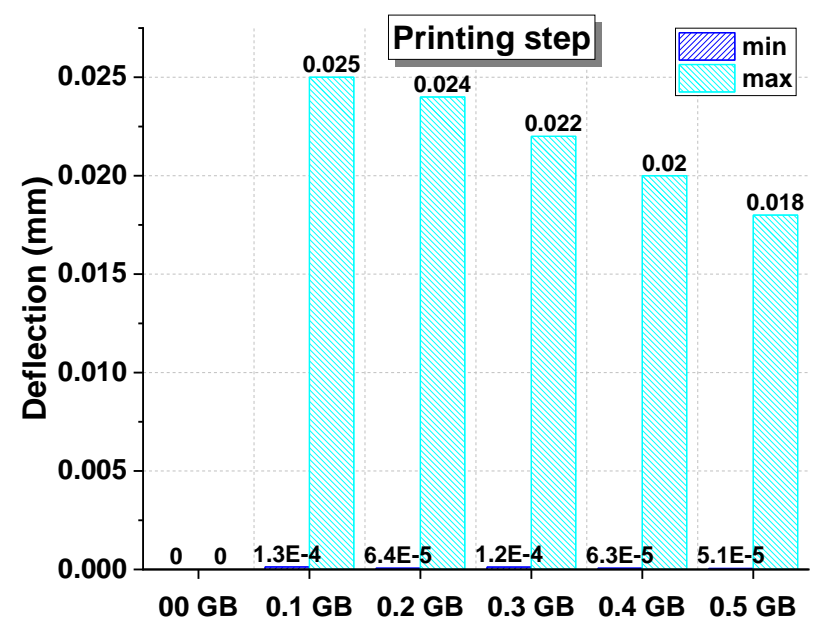

(a)

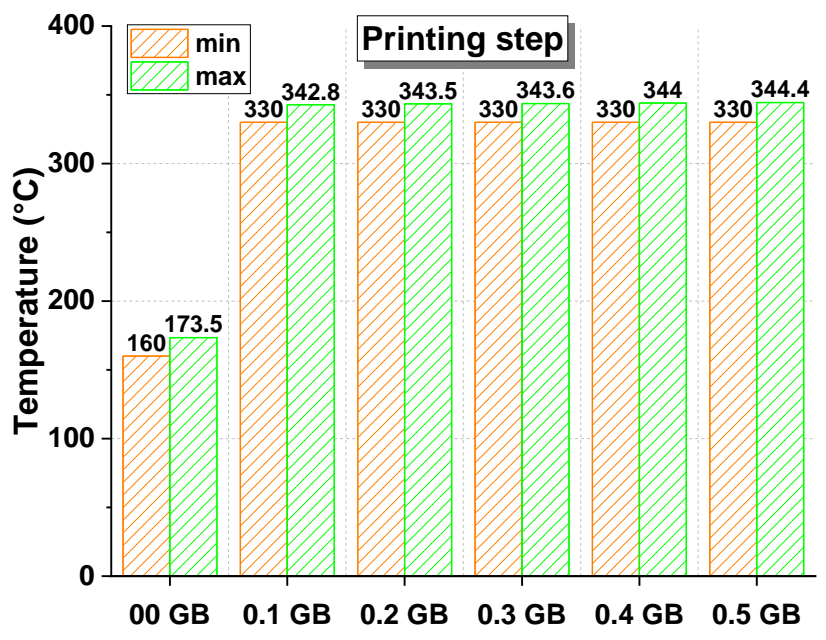

(c)

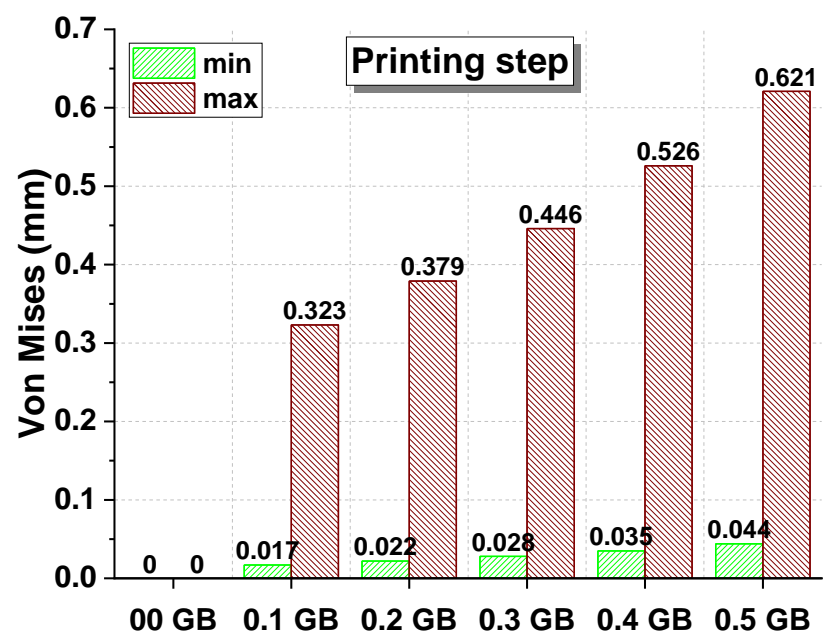

(b)

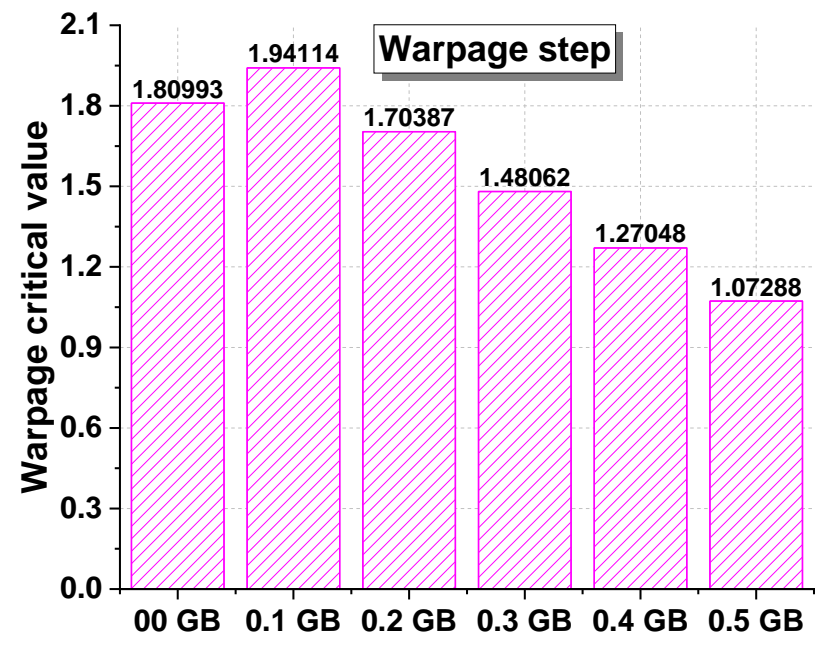

(d)

Figure 15. Thermomechanical performances of glass beads reinforced PEEK vs. volume fraction 


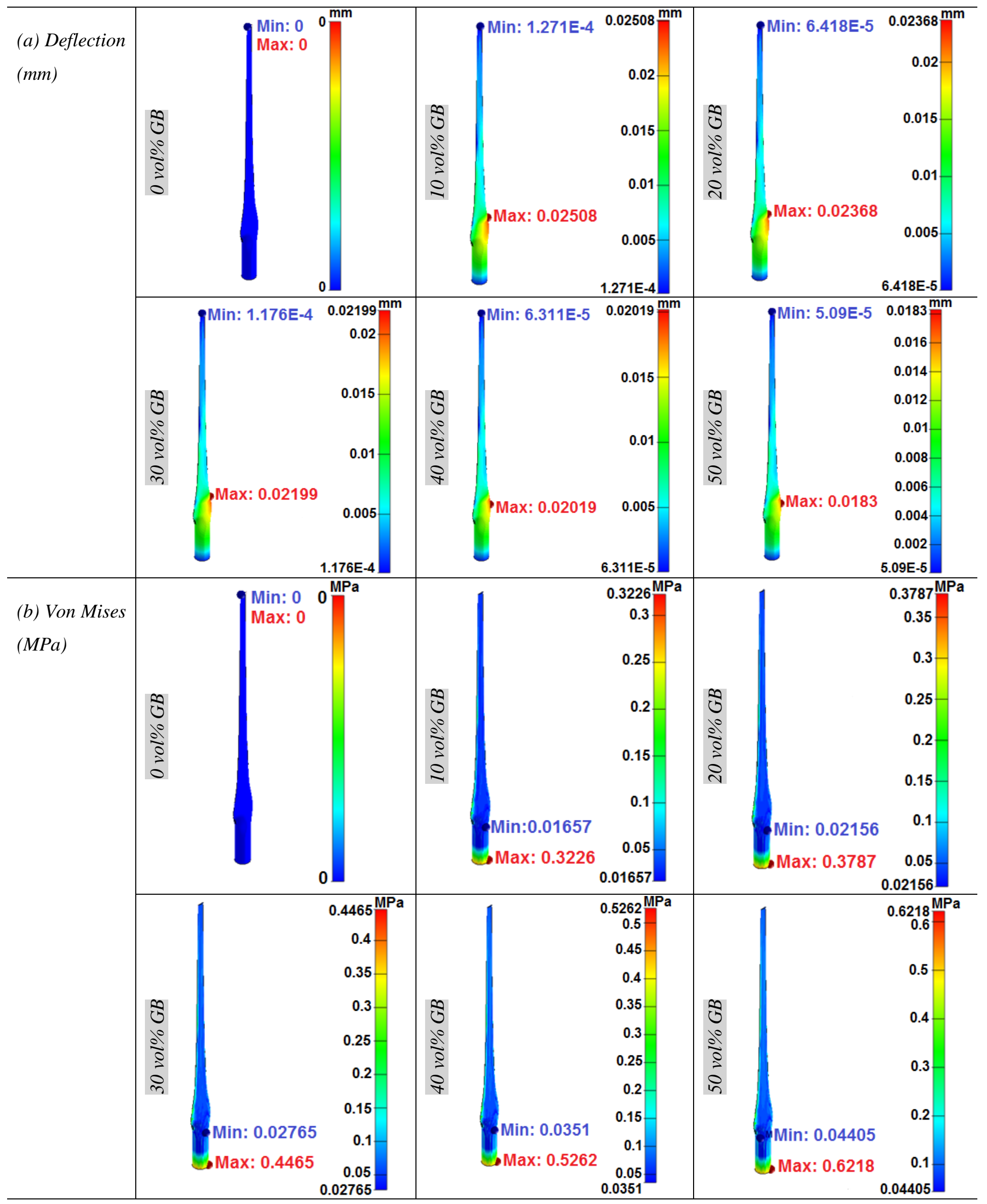

Figure 16. Deflection and residual stress (Von Mises) fields of glass beads reinforced PEEK 


\section{Discussions}

It is concluded that $\mathrm{CB}$ and GB fillers contribute to improved mechanical properties, which reduce warping and optimizes 3D manufacturing processes. A comparison of warpage at $50 \mathrm{vol} \%$ is investigated; for a specified polymer and different fillers, the warpage of PA12-GB is $3.78 \%$ lower than that of PA12-CB, but the warpage of PEEK-GB is $8.4 \%$ higher than that of PEEK-CB. On the other hand, for specified fillers and different polymers, the warpage of PA12-CB is lower than PEEKCB by $10.31 \%$, and also the warpage of PA12-GB is lower than PEEK-GB by $20.95 \%$. Therefore, the lowest averaged warpage is for PA12-GB with 1.26, and the highest averaged warpage is for PEEKGB with 1.55 as seen in Table 5 and Figure 17a, also the high warpage area (colored red) is observed in the top thin part of the tidal turbine (Figure 17b).

Table 5. Comparison of average warpage for different reinforced polymers

PA12-CB PA12-GB PEEK-CB PEEK-GB

\begin{tabular}{lllll}
\hline Average warpage & 1.26928 & 1.25779 & 1.49828 & 1.54648 \\
\hline
\end{tabular}

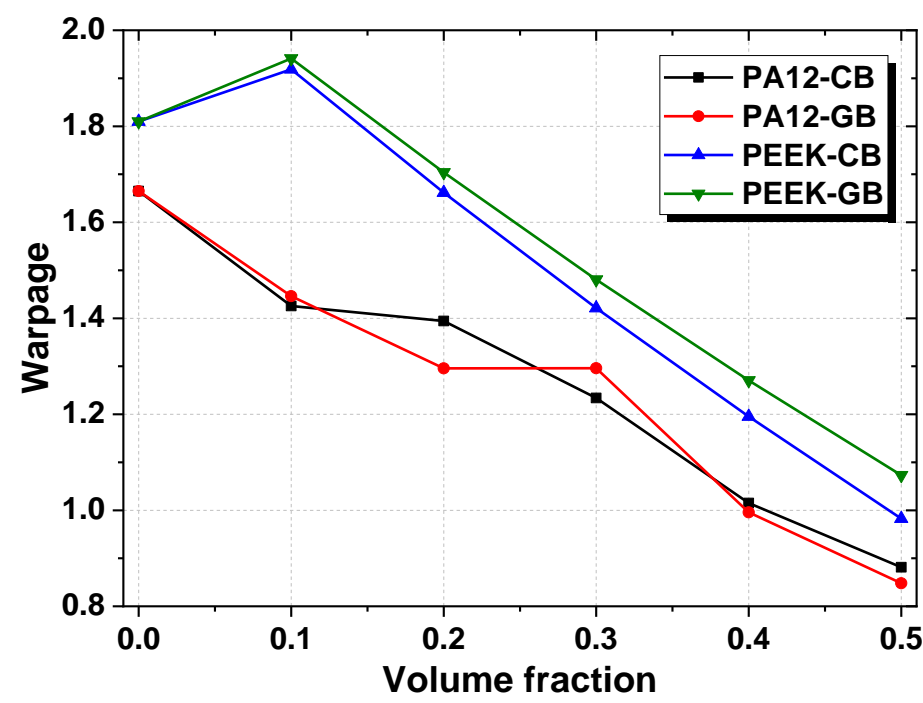

(a)

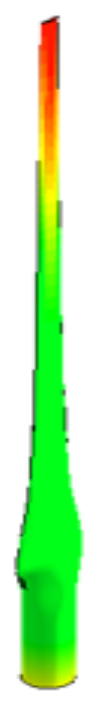

(b)

Figure 17. (a) Comparison between warpage of different reinforced polymers. (b) Distribution of warpage field 
Generally, by comparing the results for the printed tidal turbine with different materials, it is noted that the deflection distribution is different between the printing materials. Looking at the total deflection distribution, the greatest distortion is concentrated on the twisted transition part of the blade (colored red). In all these cases, it can be seen that the zones printed on first accumulate more positive deflections, while those printed on last contain the most negative deflection. Similarly, a comparison is carried out to analyze the effect of reinforcement in mechanical performance in terms of residual stress, deflection, and warpage distribution. The results showed that the three distributions are almost similar for different materials filled with carbon and glass beads, with different maximum and minimum values between them. Given the numerical results shown in the figures above, the interesting observation is that carbon and glass reinforced plastics have good strength and resistance compared to plastic non-reinforced. Finally, the blade printed with carbon-reinforced plastics has good mechanical resistance in terms of deflection and residual stress, and glass-reinforced plastics have a significant effect in reducing warpage. After all, it is concluded that components for small tidal turbines can indeed be manufactured quickly with inexpensive 3D printers. An experimental investigation is needed to predict the performance and viability of tidal turbine blades to use them in the field and this is the subject of an additional publication currently under preparation by the authors, Figure 18.

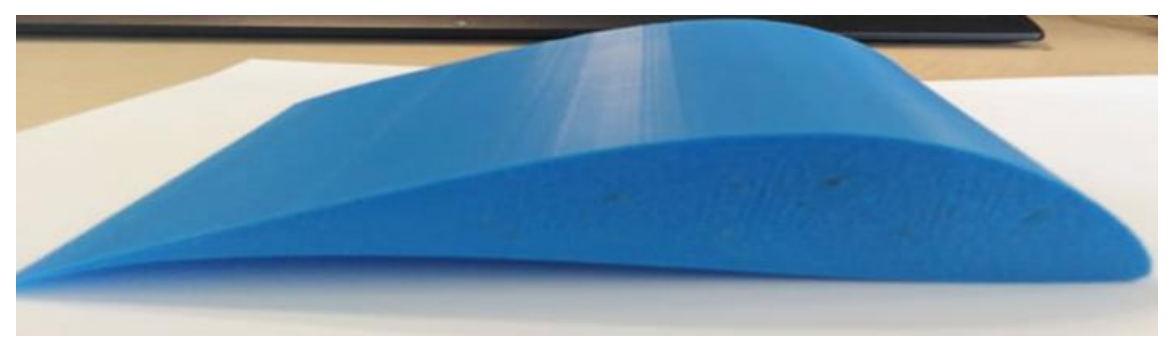

Figure 18. Experimental 3D printed NTSXX20 Hydrofoil

\section{Conclusion}

In this research project, the model of the tidal turbine blade is fabricated by the $3 \mathrm{D}$ printing process. The potential of $3 \mathrm{D}$ printing of tidal turbine blades has been evaluated in the scope of a research project. It is found that the tidal turbine blade with different blade materials can be consistent with the simulation. Through the above simulation, the tidal turbine blade with the PA12-CB has an excellent mechanical performance in terms of residual stress and deflection. In general, this preliminary study showed a high potential for 3D printing of small tidal turbine blades, but more investigations are needed to qualify this potential. Computational analysis is an effective tool for TCT design and optimization. The main observations can be presented as follows: 
- As CB and GB volume fraction increase, the deflection and warpage decrease and the residual stress and temperature increase. The maximum deflection and residual stress are observed in the twisted and first sectional layer respectively.

- PA12-CB has a warpage higher than PA12-GB by 3.78\%, and PEEK-CB has a warpage lower than PEEK-GB by $8.4 \%$. Also, the warpage of PA12-CB is lower than PEEK-CB by $10.31 \%$, and the warpage of PA12-GB is lower than PEEK-GB by $20.95 \%$.

It is concluded that the best-reinforced polymer for 3D printing:

- With the minimum warpage for PA12-GB with a value of 0.84808 .

- With the minimum residual stresses for neat PEEK with a value of $0 \mathrm{MPa}$.

\section{References}

1. Han J, Jung J, Hwang JH (2021) Optimal configuration of a tidal current turbine farm in a shallow channel. Ocean Engineering 220:108395.

https://doi.org/10.1016/j.oceaneng.2020.108395

2. Nachtane M, Tarfaoui M, Hilmi K, et al (2018) Assessment of Energy Production Potential from Tidal Stream Currents in Morocco. Energies 11:1065. https://doi.org/10.3390/en11051065

3. Tarfaoui M, Nachtane M, Amry Y, Moumen AE (2018) From Renewable to Marine Energies Sources for Sustainable Development and Energy Transition in Morocco: Current Status and Scenario. https://doi.org/10.20944/preprints201811.0568.v1

4. Nachtane M, Tarfaoui M, Goda I, Rouway M (2020) A review on the technologies, design considerations and numerical models of tidal current turbines. Renewable Energy 157:12741288. https://doi.org/10.1016/j.renene.2020.04.155

5. Seifi H, Rezaee Javan A, Xu S, et al (2018) Design optimization and additive manufacturing of nodes in gridshell structures. Engineering Structures 160:161-170.

https://doi.org/10.1016/j.engstruct.2018.01.036

6. Linke B, Garretson I, Jan F, Hafez M (2017) Integrated Design, Manufacturing and Analysis of Airfoil and Nozzle Shapes in an Undergraduate Course. Procedia Manufacturing 10:1077-1086. https://doi.org/10.1016/j.promfg.2017.07.098

7. Black Eric, Stoll Stanley C. Residential 3D Model Wind Tunnel Pressure Testing. Forensic Engineering 2015 449-467. https://doi.org/10.1061/9780784479711.044

8. Giannatsis J, Dedoussis V, Karalekas D (2002) Architectural scale modelling using stereolithography. Rapid Prototyping Journal 8:200-207.

https://doi.org/10.1108/13552540210431022

9. Zhou S, Hua XG, Chen ZQ, Chen W (2017) Experimental investigation of correction factor for VIV amplitude of flexible bridges from an aeroelastic model and its 1:1 section model.

Engineering Structures 141:263-271. https://doi.org/10.1016/j.engstruct.2017.03.023 
10. Bere P, Neamțu C (2014) DESIGN AND MANUFACTURING METHODOLOGY FOR F1 NOSE CAR. Europe and the Middle East 7

11. Kochan A (2003) Rapid prototyping helps Renault F1 Team UK improve championship prospects. Assembly Automation 23:336-339. https://doi.org/10.1108/01445150310501181

12. Forsman D, Edwards R A Rapid Prototyping Application In Wind Tunnel Testing A Student Project. 6

13. Tarfaoui M, Nachtane M, Goda I, et al (2020) 3D Printing to Support the Shortage in Personal Protective Equipment Caused by COVID-19 Pandemic. Materials 13:3339. https://doi.org/10.3390/ma13153339

14. Lin CSH, Chua CK, Yeo JH (2013) Design of high performance badminton shuttlecocks: virtual and rapid prototyping approach. Virtual and Physical Prototyping 8:165-171. https://doi.org/10.1080/17452759.2013.812738

15. Tarfaoui M, Nachtane M, Goda I, et al (2020) Additive manufacturing in fighting against novel coronavirus COVID-19. Int J Adv Manuf Technol 110:2913-2927. https://doi.org/10.1007/s00170-020-06077-0

16. Guerrero-Villar F, Torres-Jimenez E, Dorado-Vicente R, Jiménez-González JI (2015) Development of Vertical Wind Turbines via FDM Prototypes. Procedia Engineering 132:78-85. https://doi.org/10.1016/j.proeng.2015.12.482

17. Bassett K, Carriveau R, Ting DS-K (2015) 3D printed wind turbines part 1: Design considerations and rapid manufacture potential. Sustainable Energy Technologies and Assessments 11:186-193. https://doi.org/10.1016/j.seta.2015.01.002

18. Yu H, Tu Z, Xia X, et al (2014) Decentralized adaptive consensus of multi-agent in networks with switching topologies. In: 11th IEEE International Conference on Control Automation (ICCA). pp 694-699

19. Wu H, Li D, Guo N (2009) Fabrication of integral ceramic mold for investment casting of hollow turbine blade based on stereolithography. Rapid Prototyping Journal 15:232-237. https://doi.org/10.1108/13552540910979749

20. Zhang T, Yang HC, Miyamoto CM 3D Printing: A Cost Effective and Timely Approach to Manufacturing of Low-Thrust Engines. In: 50th AIAA/ASME/SAE/ASEE Joint Propulsion Conference. American Institute of Aeronautics and Astronautics

21. Rochus P, Plesseria J-Y, Van Elsen M, et al (2007) New applications of rapid prototyping and rapid manufacturing (RP/RM) technologies for space instrumentation. Acta Astronautica 61:352-359. https://doi.org/10.1016/j.actaastro.2007.01.004

22. Takato K, Shirayama S (2018) Development of a 3D-printed device evaluating the aerodynamic performance of rotary wings. Journal of Advanced Mechanical Design, Systems, and Manufacturing 12:JAMDSM0027-JAMDSM0027. https://doi.org/10.1299/jamdsm.2018jamdsm0027 
23. Ol M Water Tunnel Velocimetry Results for the 1303 UCAV Configuration. In: 24th AIAA Applied Aerodynamics Conference. American Institute of Aeronautics and Astronautics

24. Berman B (2012) 3-D printing: The new industrial revolution. Business Horizons 55:155-162. https://doi.org/10.1016/j.bushor.2011.11.003

25. Shun S, Ahmed NA (2012) Rapid Prototyping of Aerodynamics Research Models. In: Applied Mechanics and Materials. /AMM.217-219.2016. Accessed 9 Apr 2020

26. Anagnostopoulos JS, Koukouvinis PK, Stamatelos FG, Papantonis DE (2013) Optimal Design and Experimental Validation of a Turgo Model Hydro Turbine. American Society of Mechanical Engineers Digital Collection, pp 157-166

27. Howey DA, Bansal A, Holmes AS (2011) Design and performance of a centimetre-scale shrouded wind turbine for energy harvesting. Smart Mater Struct 20:085021. https://doi.org/10.1088/0964-1726/20/8/085021

28. Bak D (2003) Rapid prototyping or rapid production? 3D printing processes move industry towards the latter. Assembly Automation 23:340-345. https://doi.org/10.1108/01445150310501190

29. Bassett K, Semple L (2012) Wind turbine development for rural electrification in Nicaragua. International Journal of Environmental Studies 69:338-349. https://doi.org/10.1080/00207233.2012.663544

30. Leary J, While A, Howell R (2012) Locally manufactured wind power technology for sustainable rural electrification. Energy Policy 43:173-183. https://doi.org/10.1016/j.enpol.2011.12.053

31. www.vestas.com V- Profile. https://www.vestas.com/en/about/profile. Accessed 8 Apr 2020

32. Knight $\mathrm{S}$ New blade technology makes more from wind. http://www.windpowermonthly.com/article/1323567?utm_source=website\&utm_medium=social . Accessed 8 Apr 2020

33. Dodd J Additive manufacturing will be a "gamechanger." http://www.windpowermonthly.com/article/1421837?utm_source=website\&utm_medium=social . Accessed 8 Apr 2020

34. Poole S, Phillips R (2015) Rapid prototyping of small wind turbine blades using additive manufacturing. In: 2015 Pattern Recognition Association of South Africa and Robotics and Mechatronics International Conference (PRASA-RobMech). pp 189-194

35. Olasek K, Wiklak P (2014) Application of 3D printing technology in aerodynamic study. J Phys: Conf Ser 530:012009. https://doi.org/10.1088/1742-6596/530/1/012009

36. Nachtane M, Tarfaoui M, Saifaoui D, Rouway M (2020) Hydrodynamic performance evaluation of a new hydrofoil design for marine current turbines. Materials Today: Proceedings 30:889898. https://doi.org/10.1016/j.matpr.2020.04.346 
37. Ligon SC, Liska R, Stampfl J, et al (2017) Polymers for 3D Printing and Customized Additive Manufacturing. Chem Rev 117:10212-10290. https://doi.org/10.1021/acs.chemrev.7b00074

38. Hoskins TJ, Dearn KD, Kukureka SN (2018) Mechanical performance of PEEK produced by additive manufacturing. Polymer Testing 70:511-519. https://doi.org/10.1016/j.polymertesting.2018.08.008

39. Drummer D, Rietzel D, Kühnlein F (2010) Development of a characterization approach for the sintering behavior of new thermoplastics for selective laser sintering. Physics Procedia 5:533542. https://doi.org/10.1016/j.phpro.2010.08.081

40. Salmoria GV, Leite JL, Paggi RA, et al (2008) Selective laser sintering of PA12/HDPE blends: Effect of components on elastic/plastic behavior. Polymer Testing 27:654-659. https://doi.org/10.1016/j.polymertesting.2008.04.007 